\title{
Article \\ Ice Dendrite Growth Atop a Frozen Drop under Natural Convection Conditions
}

\author{
Chengzhi Huang ${ }^{1}$, Yugang Zhao ${ }^{1,2, * \mathbb{D}}$ and Tian Gu ${ }^{1}$ \\ 1 Shanghai Key Laboratory of Multiphase Flow and Heat Transfer in Power Engineering, School of Energy and \\ Power Engineering, University of Shanghai for Science and Technology, Shanghai 200093, China; \\ 192480085@st.usst.edu.cn (C.H.); 202390116@st.usst.edu.cn (T.G.) \\ 2 Key Laboratory of Icing and Anti/De-Icing, China Aerodynamics Research and Development Center, \\ Mianyang 621000, China \\ * Correspondence: ygzhao@usst.edu.cn
}

check for

updates

Citation: Huang, C.; Zhao, Y.; Gu, T. Ice Dendrite Growth Atop a Frozen Drop under Natural Convection Conditions. Crystals 2022, 12, 323. https://doi.org/10.3390/cryst12030323

Academic Editor: Conrad Becker

Received: 4 February 2022

Accepted: 22 February 2022

Published: 25 February 2022

Publisher's Note: MDPI stays neutral with regard to jurisdictional claims in published maps and institutional affiliations.

Copyright: (C) 2022 by the authors. Licensee MDPI, Basel, Switzerland. This article is an open access article distributed under the terms and conditions of the Creative Commons Attribution (CC BY) license (https:// creativecommons.org/licenses/by/ $4.0 /)$.

\begin{abstract}
Condensation frosting is a type of icing encountered ubiquitously in our daily lives. Understanding the dynamics of condensation frosting is essential in developing effective technologies to suppress frost accretions that compromise heat transfer and system integrity. Here, we present an experimental study on ice dendrite growth atop a single frozen drop, an important step affecting the subsequent frosting process, and the properties of fully-developed frost layers. We evaluate the effect of natural convection by comparing the growth dynamics of ice dendrites on the surface of a frozen drop with three different orientations with respect to gravity. The results show that both the average deposition rate and its spatial variations are profoundly altered by surface orientations. Such behavior is confirmed by a numerical simulation, showing how gravity-assisted (hindered) vapor diffusion yields the deposition outcomes. These findings benefit the optimization of anti-/defrosting technologies and the rational design of heat exchangers.
\end{abstract}

Keywords: condensation frosting; ice drop; dendrite growth; natural convection

\section{Introduction}

Icing, in the form of condensation frosting, is one of the most pervasive types of phase-change phenomena encountered in nature and industrial processes. While, phenomenologically, it might be trivial and slow, the undesired accretions of frost have a list of detrimental impacts in many practical scenarios. For HVAC\&R systems, frost layers engender a non-negligible thermal resistance due to densely packed micrometer-sized air pockets and, thus, inhibit heat transfer in heat exchangers, resulting in an extra energy consumption of up to $50-75 \%$ [1-4]. In cryosurgery and biochemical engineering, the contamination induced by frosting on test samples is recognized as a critical issue [5]. Frost accretions also compromise the operational performance of key facilities in power plants, infrastructure, and aviation industries [6-8]. During the past few decades, a great deal of effort has been devoted to developing effective methods to promote rapid frost removal or to suppress frost growth, referred to as "de-frosting" [9-11] and "anti-frosting" [12-14], respectively. In particular, surface designs by tailoring surface chemistry and topography to achieve so-called "icephobicity" [15-19] have shown many advantages, as these methods do not rely on intensive energy and resource inputs. However, the durability and sustainability of such surface designs are still in doubt $[20,21]$, and mitigating the frosting problem is still a long-term goal.

Understanding the dynamics in condensation frosting and revealing the associated physics is an important step for the development of new anti-/de-frosting technologies. Figure 1 shows a typical condensation frosting process, consisting of five sequential stages [22,23]: (1) heterogeneous condensation nucleation occurred at the air-substrate interface; (2) growth and coalescences of condensate drops; (3) freezing of individual drops 
and frost spreading through ice bridging; (4) growth of ice dendrites atop frozen drops (as highlighted); and (5) collapses of ice dendrites and densification. Owing to the development of new probing technologies in recent years, great advances in the fundamental understanding of condensation frosting have been achieved. These include microscopic characterizations of nucleation kinetics in both condensation and icing [24-26], ice bridging dynamics $[15,27,28]$, and in-plane growth of ice dendrites $[18,29,30]$. Based on Fletcher's classical nucleation theory (CNT) $[29,31,32]$, condensation frosting is more favorable than desublimation in most supercooling conditions. A simple fact is thus revealed: ice dendrites grow only on frozen condensate, while letting the inter-drop gaps remain dry. Therefore, investigating how ice dendrites grow on top of frozen condensate drops becomes very important, as this stage determines substantially the properties of the fully developed frost layer.

(a)

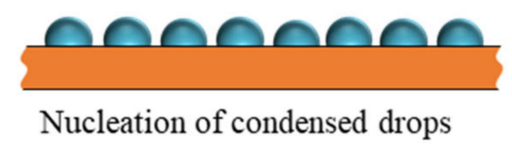

(b)

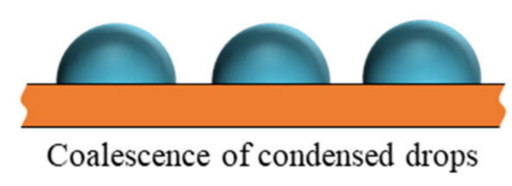

(c)

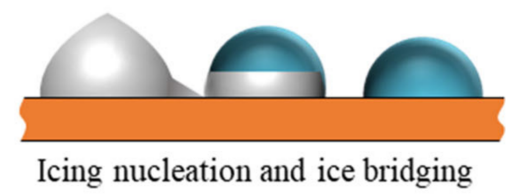

(d)

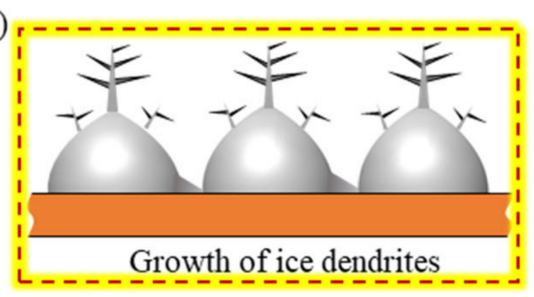

(e)

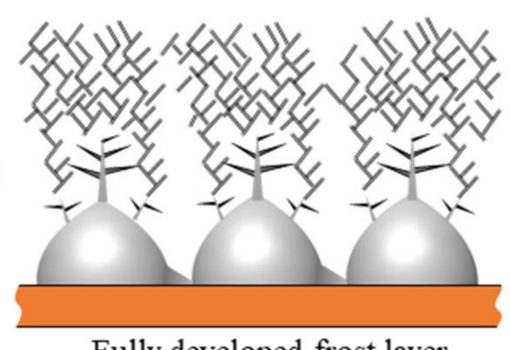

Fully developed frost layer

Figure 1. Schematic of the five sequential stages in a typical condensation frosting process [22,23]. The highlighted stage depicts the focus of this work.

Unfortunately, very little information is currently available on the quantitative characterization of the growth of ice dendrites atop frozen condensate drops. Here, we employ a direct experimental method to study the growth dynamics of ice dendrites atop a frozen water drop. To mimic the behavior of condensate drops, a millimeter-sized deionized water drop is deposited and frozen on a supercooled substrate. Once the drop completes freezing, ice dendrites start to grow at the ice-air interface, driven by a diffusion-controlled deposition with continuous vapor feeding from the ambient air. Thus, the rate of deposition can be used to evaluate quantitatively the growth speed of ice dendrites. Natural convection, sometimes ignored in convectional studies on condensation frosting, assists or hinders the transfer of water molecules in the air, and plays an important role in the growth of ice dendrites. Thereby, frosting outcomes atop a frozen drop are profoundly different if the supercooled substrate is aligned to different orientations with respect to the gravitational acceleration. This hypothesis was subsequently supported by a numerical simulation, showing that natural convection affects the concentration distribution of water vapor, which in turn changes the rate of deposition, i.e., the outcome of ice dendrite growth.

\section{Experimental Section}

We built up a customized experimental setup to observe directly the growth of ice dendrites atop a frozen water drop. Figure 2 shows the experimental setup schematically, which was comprised of a rotating cooling stage, a sample substrate, and a visualization unit. The rotating cooling stage was designed to perform two functions: delicate control of the substrate temperature at a fixed degree of supercooling while adjusting the substrate 
orientation with respect to gravity. The supercooling temperature was obtained using a dual-stage thermal controller, where stage_1 was a copper-based heat sink connected to a coolant circulator, and stage_2 was a Peltier element, the performance of which was modulated using a LabVIEW data acquisition (DAQ) module. The rotating arm which held the cooling stage was mounted on the optical table. Its three cantilever beams could adjust in-plane positions spontaneously, and thus the substrate orientation. The sample substrate was a smooth copper plate made of commercially available copper of $99.9 \%$ purity. Note that a side-view observation of drop behaviors became more phenomenal if the static contact angle was relatively large. We deliberately conducted the present study on a hydrophobic surface. An original copper plate, after going through standard polishing and pre-cleaning protocols, was silanized via chemical vapor depositing a monolayer of a fluorinated silane (trichloro $(1 \mathrm{H}, 1 \mathrm{H}, 2 \mathrm{H}, 2 \mathrm{H}$-perfluorooctyl) silane, Sigma-Aldrich, Saint Louis, MO, USA). The prepared substrate was then bonded on the center area of the cooling stage with a thin layer of thermal paste applied to minimize thermal contact resistance. The visualization unit, comprising a sCMOS camera (PCO 4.2edge, Munich, Germany), a microscopic lens, and an LED array, was employed to record the growth dynamics of ice dendrites on a frozen drop for later analysis.

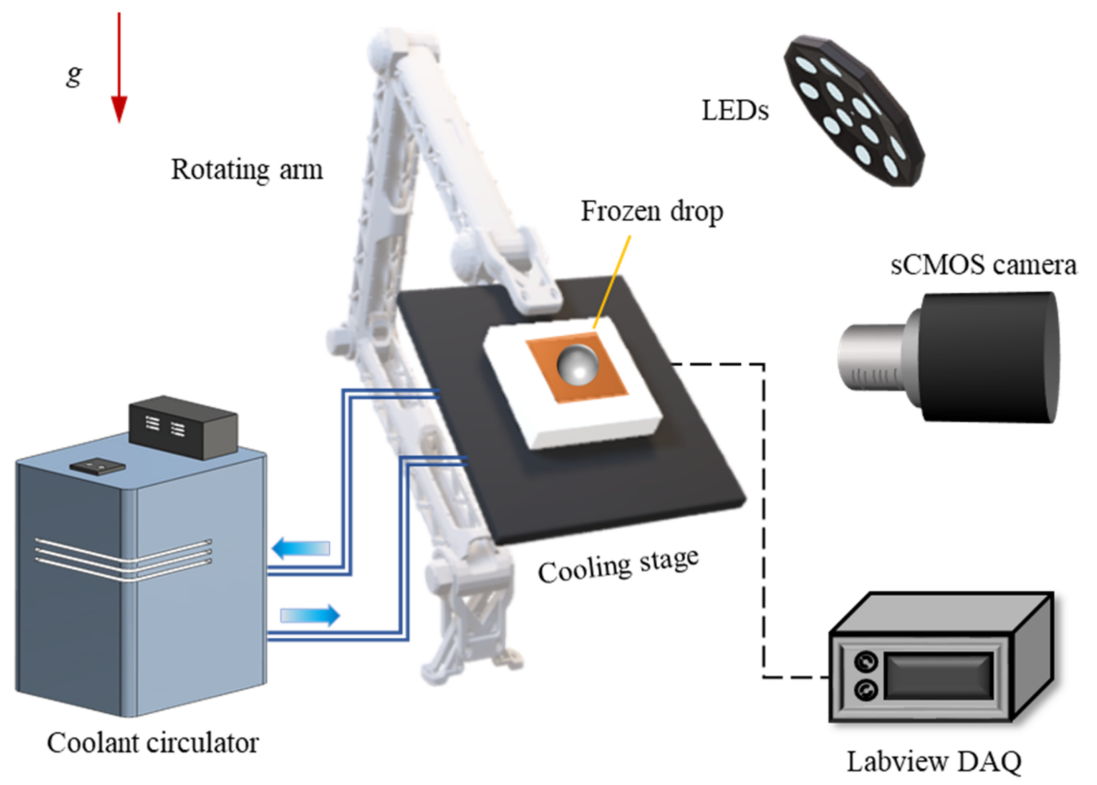

Figure 2. Schematic of the experimental setup. The substrate temperature, the ambient temperature, and relative humidity were maintained at $-15 \pm 0.1{ }^{\circ} \mathrm{C}, 18 \pm 0.2^{\circ} \mathrm{C}$, and $30 \pm 5 \%$, respectively.

This experiment was conducted in an environment exposed to natural convection in laboratory conditions. The room temperature and humidity were maintained at $18 \pm 0.2{ }^{\circ} \mathrm{C}$ and $30 \pm 5 \%$, respectively. At the beginning of the experiment, a deionized water drop, with a fixed volume of $12 \pm 0.2 \mu \mathrm{L}$, was gently deposited onto the substrate. Then, the substrate, together with the cooling stage, was rotated to a preset orientation (horizontal, vertical, and inverted). Afterward, the substrate temperature decreased rapidly, and its magnitude was stabilized and maintained at $-15 \pm 0.1^{\circ} \mathrm{C}$ in less than $20 \mathrm{~s}$. The moment when the deposited drop completed freezing, i.e., formation of a singular tip [33,34], was considered the onset of ice dendrite growth, i.e., $t_{0}=0$.

\section{Results and Discussions}

Unlike solid ice, ice dendrites are assemblies of microscale branch-like crystals, and can thus reflect more light, yielding a brighter physical appearance. Therefore, boundaries between the frozen drop and ice dendrites can be readily detected. Figure 3 shows dynamically the growth of ice dendrites atop a frozen drop from the moment the drop completes 
freezing to a relatively stable growing state over a duration of $120 \mathrm{~s}$. Note that the collapse of ice dendrites due to gravity becomes inevitable in the late frosting stage, leading to the so-called frost densification process, which has been studied extensively in the literature $[35,36]$. The straight dash-dot line indicates the axis of symmetry, while the dashed line indicates the profile of the frozen drop when the substrate is horizontally orientated.

(a)

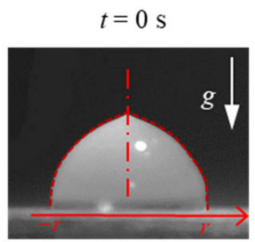

(b)

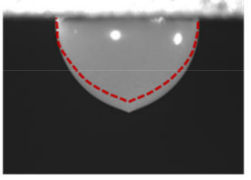

(c)

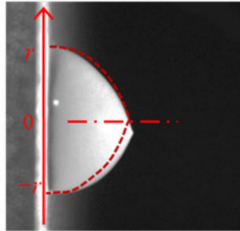

$t=30 \mathrm{~s}$
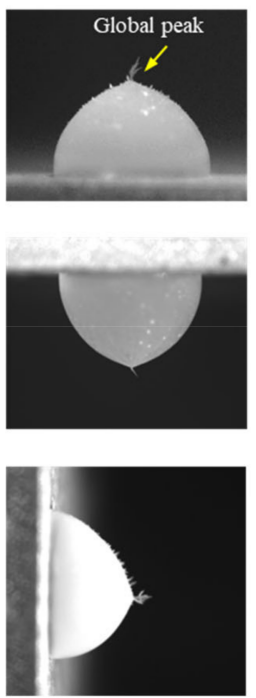

$t=60 \mathrm{~s}$
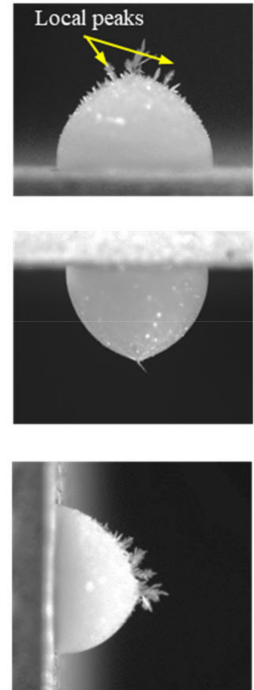

$t=120 \mathrm{~s}$
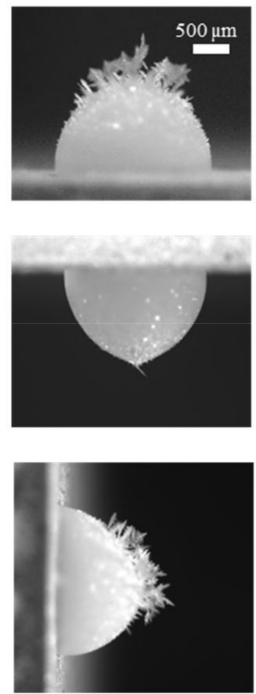

Figure 3. Growth dynamics of ice dendrites atop a frozen water drop placed on a (a) horizontally, (b) inverted, and (c) vertically orientated supercooled substrate.

For a horizontally orientated substrate as shown in Figure 3a, the frozen drop transits from a truncated sphere to a conical shape due to the expansion of water upon freezing [34,37]. At the early stage of $0 \sim 30 \mathrm{~s}$, detectable dendrites grow all over the upper portion of the frozen drop, where the smooth ice-air interface becomes rough due to the presence of ice embryos. A considerably larger growth rate occurs at the singular tip, named the "global peak". At the later stage of 30 60 s, ice dendrites grow significantly faster near a certain distance away from the singular tip, yielding two secondary "local peaks". The growth of ice dendrites is suppressed between the gaps of "global peak" and "local peaks", yielding depletion zones. At the last stage of $60 \sim 120 \mathrm{~s}$, the upper portion of the frozen drop is covered with an appreciable amount of ice dendrites, and the growth amount decreases as it descends along the ice-air interface. For an inverted substrate as shown in Figure 3b, the frozen drop is slightly prolonged along the vertical direction due to the effect of gravity. At the early stage of $0 \sim 30 \mathrm{~s}$, the ice-air interface also becomes rough due to the presence of ice embryos, similarly to the horizontal case. However, the growth rate of ice dendrites is so small that we could barely detect the increment of ice dendrite growth with the exception of the "global peak" at the following stages of 30 60 s and $60 \sim 120$ s. For a vertically orientated substrate, as shown in Figure 3c, the frozen drop is unsymmetrical as in the other two cases. The singular tip still exists with its location shifting slightly downwards along the vertical direction. At the early stage of $0 \sim 30 \mathrm{~s}$, the upper portion ( $>50 \%$ of the drop, from the top leading edge to the singular tip) of the frozen drop is covered with discrete slim ice dendrites. Unlike the other two cases, the ice-air interface remains smooth at the bottom portion of the frozen drop, with no sign of detectable ice embryo. The maximum growth rate is also observed at the singular tip. At the following stages of 30 60 s and 60 120 s, ice dendrites gradually grow and cover the upper portion of the frozen drop, where the growth rate is relatively uniform, and thus, the difference between the global peak and local peak is insignificant. Ice embryos eventually start to emerge at the ice-air interface of the bottom portion. Note that we are neglecting the 
topological features of ice dendrites and instead only focusing on the size of ice dendrites at specific locations and how it changes for the varying orientations of the substrate.

To obtain a quantitative description of the growth of ice dendrites atop a frozen drop, we adopted a MATLAB-based image processing program for the subsequent data analysis. Shown in Figure 4 is an example illustrating how the amount of deposition, i.e., the growth of ice dendrites, is extracted from a snapshot of one experiment ( $t=60 \mathrm{~s}$ for a horizontally orientated substrate used for the demo). The image processing program consists of three sequential steps: (1) an image calculation is processed by subtracting the background, which is the snapshot at the moment when the main drop completes freezing $t=0 \mathrm{~s}$; (2) a proper grey value is chosen as the threshold, based on which the calculated image is transformed into a binary, i.e., grey value of 0 or 255 for the dark background and ice dendrites, respectively; and (3) by dividing the contact line into several columns, we can obtain the amount of deposition as a function of base location and time, $Q_{\text {ice }}=\rho_{\text {ice }} h(r, t)$, with $\rho_{\text {ice }}$ being the density of ice, and $h$ the average height of ice dendrites in each column. Thereby, the amount of deposition $Q_{\text {ice }}$ can be described in terms of $\mathrm{g} / \mathrm{mm}^{2}$, i.e., weight per unit area along the ice-air interface.

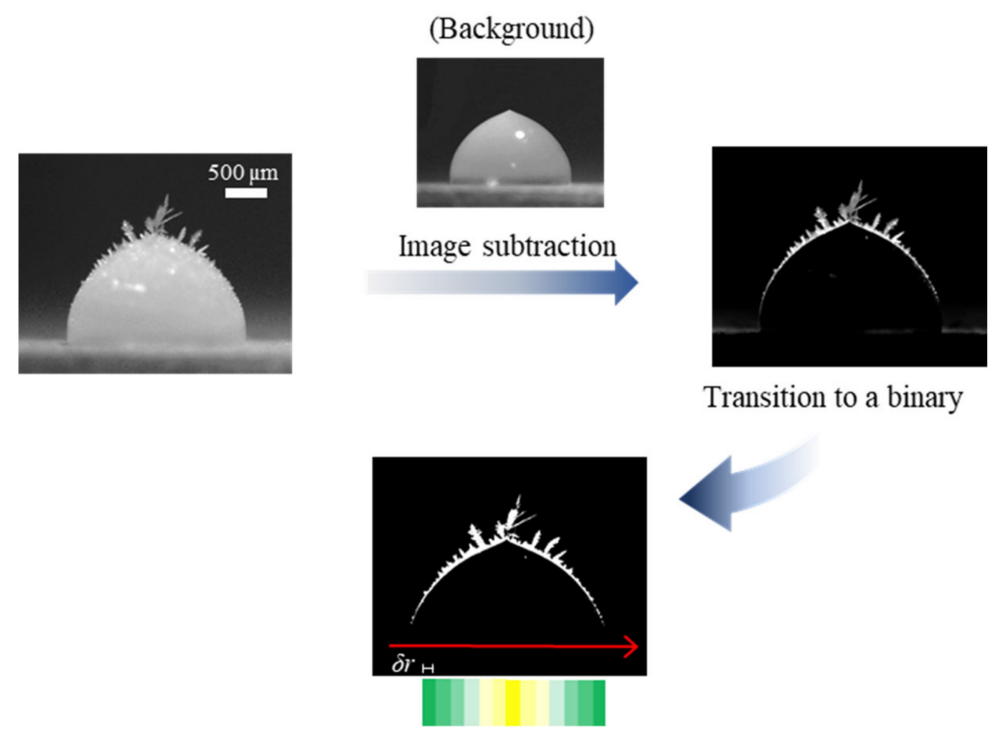

Figure 4. An example showing how the amount of deposition atop a single frozen drop is calculated from direct experimental captures using a MATLAB-based image processing approach.

Figure 5 shows the amount of deposition calculated for three different surface orientations. Each group of data is obtained based on 12 14 individual measurements. For a horizontally orientated substrate, as shown in Figure $5 \mathrm{a}$, the maximum amount of deposition (approx. $162 \mu \mathrm{g} / \mathrm{mm}^{2}$ ) occurs at the singular tip, and the amount of deposition is axial symmetric throughout the whole deposition process. Two local peaks and their companied depletion zones emerge at the stage of 30 60 s. However, as the deposition continues, local peaks coalesce into the global peak, and the depletion zones disappear at the stage of $60 \sim 120 \mathrm{~s}$. Finally, the amount of deposition decreases monotonically from the singular tip down to the drop edges. For an inverted substrate as shown in Figure $5 b$, the amount of deposition is much smaller than that of the other two cases. The maximum amount of deposition (approx. $49 \mu \mathrm{g} / \mathrm{mm}^{2}$ ) also occurs at the singular tip. However, the amount of deposition decreases drastically away from the singular tip, and there is no sign of a detectable local peak. For a vertically orientated substrate as shown in Figure $5 c$, the amount of deposition is asymmetric along the contact line, and its maximum value (approx. $171 \mu \mathrm{g} / \mathrm{mm}^{2}$ ) at the singular tip is slightly larger than that of the adjacent area in the upper portion of the frozen drop. Unlike that of the horizontally orientated substrate, there is only one local peak that also coalesces into the global peak at the stage of $60 \sim 120 \mathrm{~s}$. From the singular tip (at $r / r_{0} \approx-0.2$ ) to a certain distance (at $r / r_{0} \approx 0.8$ ) in the upper portion of 
the frozen drop, an appreciable large amount of deposition occurs, while its magnitude decreases drastically away from this region.

(a)

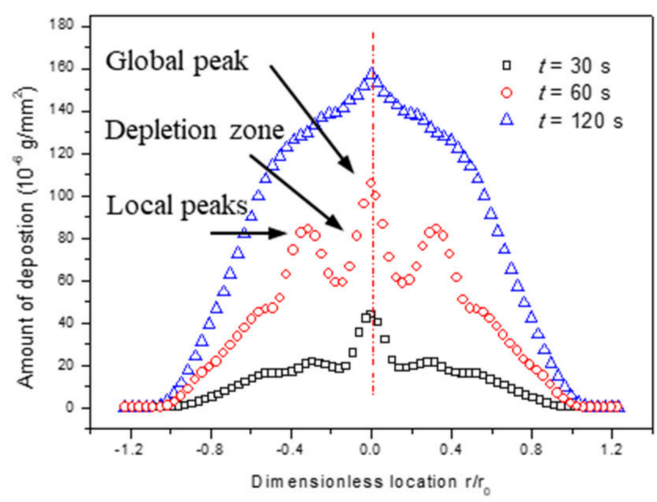

(b)

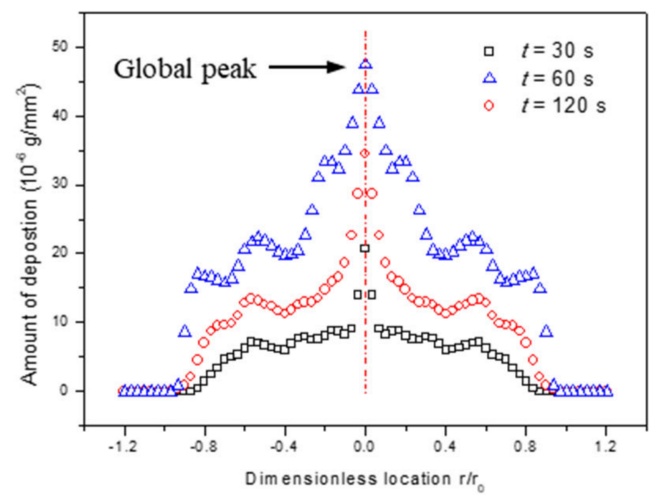

(c)

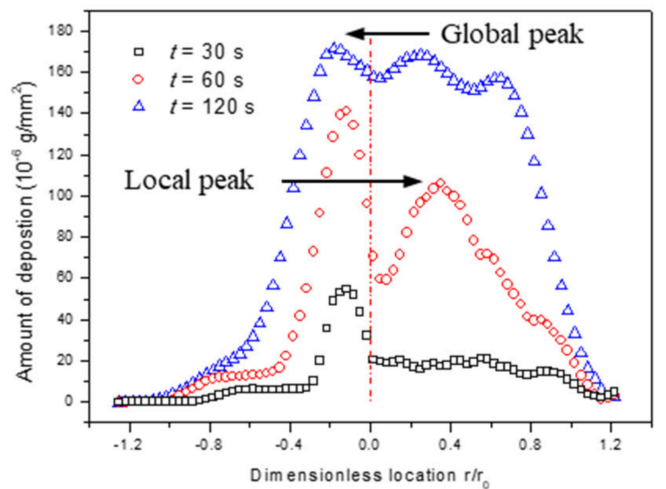

Figure 5. Variation of the amount of deposition against the contact radius for the cases of a horizontally (a), inverted (b), and vertically (c) orientated substrate, respectively. $r_{0}$ is the contact radius. Each group of data is computed based on 12-14 individual measurements.

To explain why the surface orientation has such a strong impact on the growth of ice dendrites atop a frozen drop, the problem is simplified to the deposition of water vapor on the ice-air interface. Note that we neglect the intrinsic anisotropic dendrite growth due to the molecule structure of ice [38], and instead only focus on mass transfer in the gaseous phase. As shown in Figure 6a, the physics is formulated into a binary (i.e., water vapor in the air) diffusion problem under natural convection conditions. 
(a)
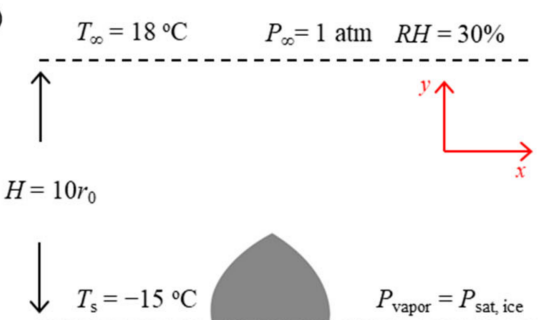

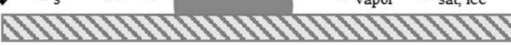

(c)
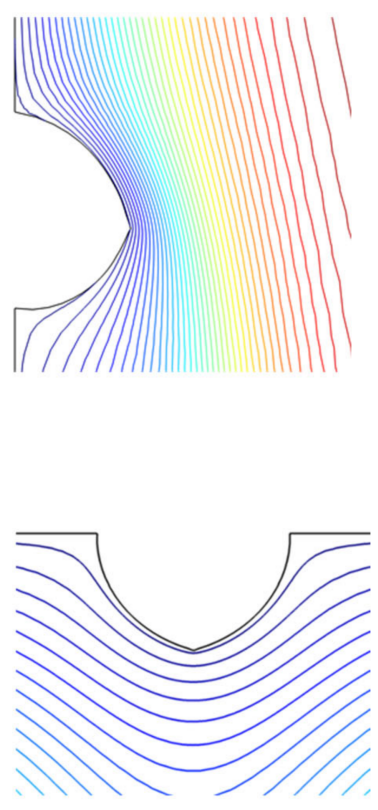

(d)

(b)

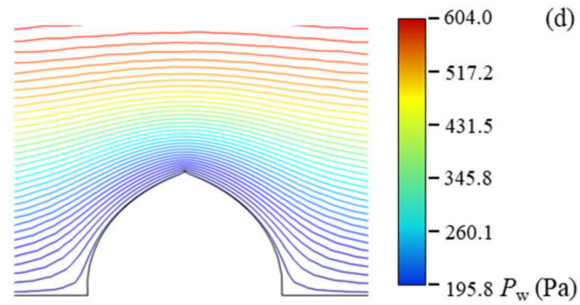

Figure 6. Modeling details and results. (a) Schematic of the computing domain and the boundary conditions. (b-d) Show the distribution of water vapor pressure for the three substrate alignments.

First, similar to the case of evaporation [39,40], we assume that a laminar sublayer $\delta$ exists in the vicinity of the supercooled substrate, where the concentration of water vapor changes drastically from the saturated concentration at the ice-air interface to the equilibrium concentration in the ambient air. In this work, we choose $\delta=10 r_{0}$ which defines the space for calculation. Note that in this problem, the vapor diffusion is intrinsically induced by the temperature difference. As the characteristic time for heat transfer $t \sim \delta^{2} / \alpha \sim 10^{-1} \mathrm{~s}$, with $\alpha=1 \times 10^{-5} \mathrm{~m}^{2} / \mathrm{s}$ being thermal diffusivity of vapor, is much smaller than the observation time $\sim 120 \mathrm{~s}$, we can assume that the deposition occurs in a pseudo-steady state. A finite element method (FEM) based commercial software (COMSOL Multiphysics 4.3a) was adopted to solve the following coupled governing equations for a steady laminar flow [41]:

Momentum equation for $\mathrm{x}, \mathrm{y}$ components:

$$
\begin{gathered}
u \frac{\partial u}{\partial x}+v \frac{\partial u}{\partial y}=-\frac{1}{\rho_{\text {avg }}} \frac{\partial P}{\partial x}+\frac{\mu}{\rho_{\text {avg }}}\left(\frac{\partial^{2} u}{\partial x^{2}}+\frac{\partial^{2} u}{\partial y^{2}}\right) \\
u \frac{\partial v}{\partial x}+v \frac{\partial v}{\partial y}=-\frac{1}{\rho_{\text {avg }}} \frac{\partial P}{\partial y}+\frac{\mu}{\rho_{\text {avg }}}\left(\frac{\partial^{2} v}{\partial x^{2}}+\frac{\partial^{2} v}{\partial y^{2}}\right)+g \beta\left(T-T_{\infty}\right)
\end{gathered}
$$

Energy equation:

$$
u \frac{\partial T}{\partial x}+v \frac{\partial T}{\partial y}=\alpha\left(\frac{\partial^{2} T}{\partial x^{2}}+\frac{\partial^{2} T}{\partial y^{2}}\right)
$$

Concentration equation:

$$
u \frac{\partial c}{\partial x}+v \frac{\partial c}{\partial y}=D\left(\frac{\partial^{2} c}{\partial x^{2}}+\frac{\partial^{2} c}{\partial y^{2}}\right)
$$

where $\beta$ is the coefficient of thermal expansion at $T_{\text {avg }}=\left(T_{S}+T_{\infty}\right) / 2$, and $D=2.6 \times 10^{-5} \mathrm{~m}^{2} / \mathrm{s}$ is the diffusivity of water molecules in air at room temperature. Note that we adopt the Boussinesq approximation [42,43], i.e., density $\rho=\left(\rho_{S}+\rho_{\infty}\right) / 2$ is constant except in the last term of $y$-momentum in Equation (2), $\rho=\rho_{\infty} \frac{1}{1+\beta\left(T-T_{\infty}\right)}$. We also assume that the mixture (water vapor and air) obeys the ideal gas law, giving $c=P_{w} M / R T$, where $M$ is 
the molar weight of water, $P_{W}$ is the vapor partial pressure, and $R$ is the universal gas constant $[15,40]$.

Figure $6 \mathrm{~b}-\mathrm{d}$ show the computed results of vapor pressure for the horizontally, vertically, and inverted orientated surfaces, respectively. As the growth of ice dendrites is considered as the diffusion-controlled deposition of water vapor, the concentration gradient, i.e., the density of constant vapor pressure lines, can be used to evaluate the growth rate of ice dendrites. The maximum concentration gradient occurs at the singular tip for a horizontally orientated substrate and in a region from the singular tip to a certain distance in the upper portion of the frozen drop for a vertically orientated substrate. Geometrical singularities, such as the tips, naturally induce large gradients of local vapor pressure, and thus strong vapor fluxes, making them preferential sites for the deposition. This behavior is completely analogous to the way how a lightning rod works, i.e., by providing the fastest path for the passing of electrical charges. The concentration gradient for an inverted substrate is much smaller than the other cases. Note that this model does not include any moving interfaces, such as how the ice dendrites formed in an earlier stage affect the subsequent vapor deposition, and thus the formation of local peaks and depletion zones cannot be described. Similar results have been obtained at the substrates with topological features instead of attached frozen drops [44-47], where the contribution of gravity is excluded. The role of gravity is quite clear in this work, i.e., it promotes the deposition when it occurs along with gravity, while it hinders or retards the deposition when it occurs against gravity.

To further elaborate the concept in this work, we also investigated the growing dynamics of ice dendrites at different supercooling temperatures. When the substrate temperature $T_{S}$ is of a smaller degree of supercooling $\left(T_{s}=-10 \pm 0.1^{\circ} \mathrm{C}\right)$, as shown in Figure $7 \mathrm{a}$, vapor transfer is at least partially dominated by diffusion, which is independent of gravity. Ice dendrites grow both on the upper and bottom portions of the frozen drop at the late stage of our interest $t=120 \mathrm{~s}$. However, at the larger degree of supercooling $\left(T_{s}=-20 \pm 0.1^{\circ} \mathrm{C}\right)$ as shown in Figure 7b, natural convection is significantly overcoming diffusion, and thus ice dendrites grow much faster at the upper portion of the frozen drop where vapor transfers along with gravity. On the contrary, ice dendrites grow much slower at the bottom portion of the frozen drop where vapor transfers against gravity.

(a)

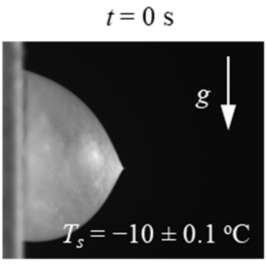

(b)

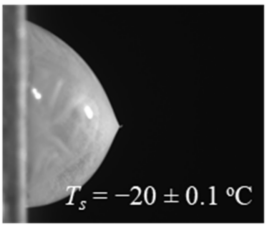

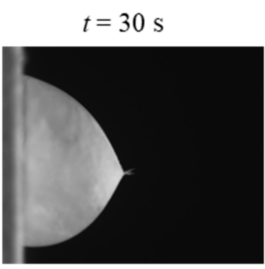

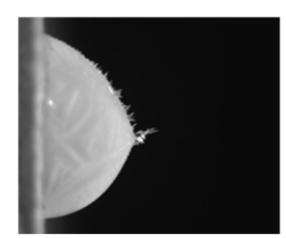

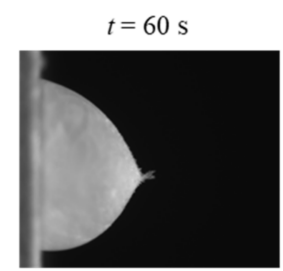

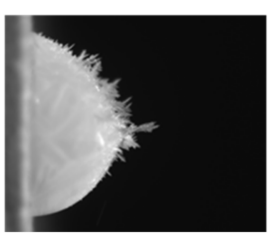

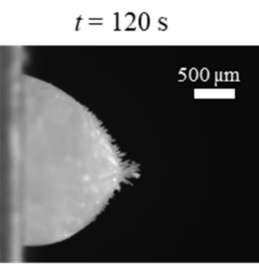

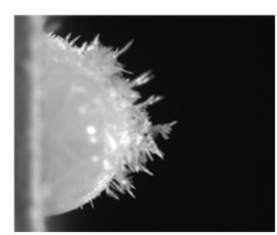

Figure 7. Growth dynamics of ice dendrites atop a frozen water drop placed on a vertically orientated substrate at (a) $T_{S}=-10 \pm 0.1{ }^{\circ} \mathrm{C}$, and (b) $T_{S}=-20 \pm 0.1^{\circ} \mathrm{C}$.

In many practical scenarios, such as frosting on cryogenics and refrigeration heat exchangers, ice dendrites grow on top of densely packed micrometer-sized condensate drops, and thus an in situ observation of ice dendrites growing atop a single frozen drop is difficult. This work provides some guidance on how ice dendrites grow in such scenarios. Figure 8 shows the frosting behavior in a commercial freezer when exposing the chamber to warm humid ambient air for $2 \mathrm{~h}$. The growth of ice dendrites atop condensate drops located at the ceiling, sidewall, and bottom of the chamber can be anticipated based on the concept 
from this work. Note that the growth of ice dendrites atop condensate drops determines subsequent frosting steps, and thus properties of fully developed frosting layers, such as packing density and thermal conductivity.

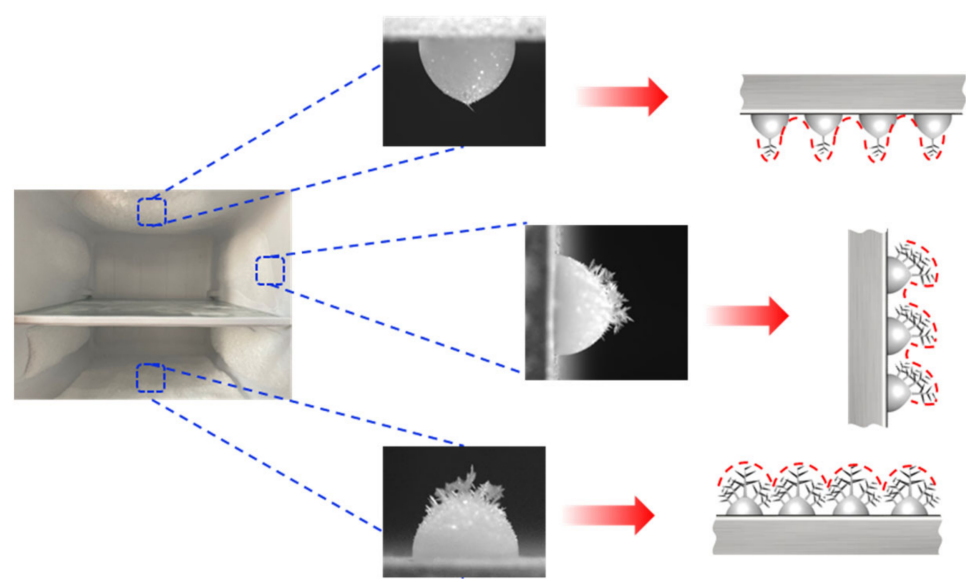

Figure 8. A practical scenario (frosting in a home freezer when leaving the chamber open for $2 \mathrm{~h}$ ) chosen to illustrate the effect of substrate orientation on the growth of ice dendrites atop a frozen drop and the resultant profile of the frost layer.

\section{Conclusions}

In this work, we perform an experimental study on the growth of ice dendrites atop a single frozen drop, an important step affecting the subsequent frosting and properties of fully developed frost layers. We evaluate the effects of natural convection by comparing the growing dynamics of ice dendrites on frozen drops with three different surface orientations. The results show that both the average deposition rate and its spatial variation are profoundly altered by surface orientations. We also constructed a numerical model showing how gravity assists or hinders the diffusion of water vapor, resulting in different deposition outcomes. We believe that results obtained in this paper can shed light on the fundamental understanding of condensation frosting and the formation of other forms of ice, such as ice particles, snow, graupel, and hail. This work also benefits the rational design of anti-/de-frosting technologies in heat exchangers.

Author Contributions: Conceptualization, Y.Z.; methodology, C.H. and Y.Z.; formal analysis, C.H., T.G. and Y.Z.; investigation, C.H., T.G. and Y.Z.; writing—original draft preparation, C.H. and Y.Z.; writing - review and editing, Y.Z.; supervision, Y.Z.; funding acquisition, Y.Z. All authors have read and agreed to the published version of the manuscript.

Funding: This research was funded by the Experiments for Space Exploration Program and the Qian Xuesen Laboratory, China Academy of Space Technology (Grant No. TKTSPY-2020-01-01) to Y.Z., Open Fund of Key Laboratory of Icing and Anti/De-icing (Grant No. IADL20200103) to Y.Z., National Key R\&D Program of China (Grant No. 2020YFF0303901), and the Program for Professor of Special Appointment (Eastern Scholar) at Shanghai Institutions of Higher Learning to Y.Z.

Institutional Review Board Statement: Not applicable.

Informed Consent Statement: Not applicable.

Data Availability Statement: Data sharing not applicable.

Conflicts of Interest: The authors declare no conflict of interest.

\section{References}

1. Lv, J.; Song, Y.; Jiang, L.; Wang, J. Bio-Inspired Strategies for Anti-Icing. ACS Nano 2014, 8, 3152-3169. [CrossRef]

2. Huang, L.; Liu, Z.; Liu, Y.; Gou, Y.; Wang, J. Experimental study on frost release on fin-and-tube heat exchangers by use of a novel anti-frosting paint. Exp. Therm. Fluid Sci. 2009, 33, 1049-1054. [CrossRef] 
3. Zhao, G.; Zou, G.; Wang, W.; Geng, R.; Yan, X.; He, Z.; Liu, L.; Zhou, X.; Lv, J.; Wang, J. Competing Effects between Condensation and Self-Removal of Water Droplets Determine Antifrosting Performance of Superhydrophobic Surfaces. ACS Appl. Mater. Interfaces 2020, 12, 7805-7814. [CrossRef]

4. Li, L.; Liu, Z.; Zhao, L.; Li, Y. The theoretical analysis and experimental study on anti-frosting performance of surface characteristics. Int. J. Therm. Sci. 2019, 137, 343-351. [CrossRef]

5. John Morris, G.; Acton, E. Controlled ice nucleation in cryopreservation-A review. Cryobiology 2013, 66, 85-92. [CrossRef]

6. Laforte, J.L.; Allaire, M.A.; Laflamme, J. State-of-the-art on power line de-icing. Atmos. Res. 1998, 46, 143-158. [CrossRef]

7. Cebeci, T.; Kafyeke, F. Aircraft Icing. Annu. Rev. Fluid Mech. 2003, 35, 11-21. [CrossRef]

8. Zhu, Z.; Zhang, X.; Zhao, Y.; Huang, X.; Yang, C. Freezing characteristics of deposited water droplets on hydrophilic and hydrophobic cold surfaces. Int. J. Therm. Sci. 2022, 171, 107241. [CrossRef]

9. De Koninck, L.H.; Ahmadi, S.F.; Boreyko, J.B. Passive anti-frosting cables. Int. J. Heat Mass Transf. 2020, 146, 118808. [CrossRef]

10. Dash, S.; de Ruiter, J.; Varanasi, K.K. Photothermal trap utilizing solar illumination for ice mitigation. Sci. Adv. 2018, 4, eaat0127. [CrossRef]

11. Mitridis, E.; Schutzius, T.M.; Sicher, A.; Hail, C.U.; Eghlidi, H.; Poulikakos, D. Metasurfaces Leveraging Solar Energy for Icephobicity. ACS Nano 2018, 12, 7009-7017. [CrossRef] [PubMed]

12. Li, T.; Ibáñez-Ibáñez, P.F.; Håkonsen, V.; Wu, J.; Xu, K.; Zhuo, Y.; Luo, S.; He, J.; Zhang, Z. Self-Deicing Electrolyte Hydrogel Surfaces with Pa-level Ice Adhesion and Durable Antifreezing/Antifrost Performance. ACS Appl. Mater. Interfaces 2020, 12, 35572-35578. [CrossRef] [PubMed]

13. He, Z.; Zhuo, Y.; Wang, F.; He, J.; Zhang, Z. Understanding the role of hollow sub-surface structures in reducing ice adhesion strength. Soft Matter 2019, 15, 2905-2910. [CrossRef]

14. Zhao, Y.; Yan, Z.; Zhang, H.; Yang, C.; Cheng, P. Promote anti- /de- frosting by suppressing directional ice bridging. Int. J. Heat Mass Transf. 2021, 165, 120609. [CrossRef]

15. Zhao, Y.; Yang, C. Retarded condensate freezing propagation on superhydrophobic surfaces patterned with micropillars. Appl. Phys. Lett. 2016, 108, 061605. [CrossRef]

16. Mukherjee, R.; Ahmadi, S.F.; Zhang, H.; Qiao, R.; Boreyko, J.B. Electrostatic Jumping of Frost. ACS Nano 2021, $15,4669-4677$. [CrossRef] [PubMed]

17. Nath, S.; Ahmadi, S.F.; Boreyko, J.B. How ice bridges the gap. Soft Matter 2020, 16, 1156-1161. [CrossRef]

18. Lo, C.-W.; Sahoo, V.; Lu, M.-C. Control of Ice Formation. ACS Nano 2017, 11, 2665-2674. [CrossRef]

19. Jung, S.; Tiwari, M.K.; Poulikakos, D. Frost halos from supercooled water droplets. Proc. Natl. Acad. Sci. USA 2012, 109, 16073-16078. [CrossRef]

20. Dodiuk, H.; Kenig, S.; Dotan, A. Do Self-cleaning Surfaces Repel Ice? J. Adhes. Sci. Technol. 2012, 26, 701-714. [CrossRef]

21. Zhao, Y.; Wang, R.; Yang, C. Interdroplet freezing wave propagation of condensation frosting on micropillar patterned superhydrophobic surfaces of varying pitches. Int. J. Heat Mass Transf. 2017, 108, 1048-1056. [CrossRef]

22. Nath, S.; Ahmadi, S.F.; Boreyko, J.B. A Review of Condensation Frosting. Nanoscale Microscale Thermophys. Eng. 2017, $21,81-101$. [CrossRef]

23. Zhao, Y.; Guo, Q.; Lin, T.; Cheng, P. A review of recent literature on icing phenomena: Transport mechanisms, their modulations and controls. Int. J. Heat Mass Transf. 2020, 159, 120074. [CrossRef]

24. Hou, Y.; Yu, M.; Shang, Y.; Zhou, P.; Song, R.; Xu, X.; Chen, X.; Wang, Z.; Yao, S. Suppressing Ice Nucleation of Supercooled Condensate with Biphilic Topography. Phys. Rev. Lett. 2018, 120, 075902. [CrossRef]

25. Sun, X.; Damle, V.G.; Liu, S.; Rykaczewski, K. Bioinspired Stimuli-Responsive and Antifreeze-Secreting Anti-Icing Coatings. Adv. Mater. Interfaces 2015, 2, 1400479. [CrossRef]

26. Gurganus, C.; Kostinski, A.B.; Shaw, R.A. High-Speed Imaging of Freezing Drops: Still No Preference for the Contact Line. J. Phys. Chem. C 2013, 117, 6195-6200. [CrossRef]

27. Boreyko, J.B.; Collier, C.P. Delayed Frost Growth on Jumping-Drop Superhydrophobic Surfaces. ACS Nano 2013, 7, 1618-1627. [CrossRef] [PubMed]

28. Guadarrama-Cetina, J.; Mongruel, A.; González-Viñas, W.; Beysens, D. Percolation-induced frost formation. EPL Europhys. Lett. 2013, 101, 16009. [CrossRef]

29. Ahmadi, S.F.; Nath, S.; Iliff, G.J.; Srijanto, B.R.; Collier, C.P.; Yue, P.; Boreyko, J.B. Passive Antifrosting Surfaces Using Microscopic Ice Patterns. ACS Appl. Mater. Interfaces 2018, 10, 32874-32884. [CrossRef]

30. Zhao, Y.; Zuo, Z.; Tang, H.; Zhang, X. Ice Coverage Induced by Depositing a Water Drop onto the Supercooled Substrate at Extreme Low Vapor Pressure. Crystals 2021, 11, 691. [CrossRef]

31. Fletcher, N.H. The Chemical Physics of Ice; Cambridge University Press: Cambridge, UK, 1970.

32. Walker, C.; Lerch, S.; Reininger, M.; Eghlidi, H.; Milionis, A.; Schutzius, T.M.; Poulikakos, D. Desublimation Frosting on Nanoengineered Surfaces. ACS Nano 2018, 12, 8288-8296. [CrossRef] [PubMed]

33. Marín, A.G.; Enríquez, O.R.; Brunet, P.; Colinet, P.; Snoeijer, J.H. Universality of Tip Singularity Formation in Freezing Water Drops. Phys. Rev. Lett. 2014, 113, 054301. [CrossRef] [PubMed]

34. Zhao, Y.; Yang, C.; Cheng, P. Freezing of a nanofluid droplet: From a pointy tip to flat plateau. Appl. Phys. Lett. 2021, 118, 141602. [CrossRef] 
35. Tao, Y.X.; Besant, R.W.; Rezkallah, K.S. A mathematical model for predicting the densification and growth of frost on a flat plate. Int. J. Heat Mass Transf. 1993, 36, 353-363. [CrossRef]

36. Song, M.; Dang, C. Review on the measurement and calculation of frost characteristics. Int. J. Heat Mass Transf. 2018, 124, 586-614. [CrossRef]

37. Zhang, H.; Zhao, Y.; Lv, R.; Yang, C. Freezing of sessile water droplet for various contact angles. Int. J. Therm. Sci. 2016, 101, 59-67. [CrossRef]

38. Guo, Q.; Cheng, P. Numerical investigations of six-fold dendritic icing process in subcooled water subject to natural and forced convective environments. Int. J. Heat Mass Transf. 2019, 145, 118658. [CrossRef]

39. Galenko, P.K.; Funke, O.; Wang, J.; Herlach, D.M. Kinetics of dendritic growth under the influence of convective flow in solidification of undercooled droplets. Mater. Sci. Eng. A 2004, 375-377, 488-492. [CrossRef]

40. Starov, V.; Sefiane, K. On evaporation rate and interfacial temperature of volatile sessile drops. Colloids Surf. A Physicochem. Eng. Asp. 2009, 333, 170-174. [CrossRef]

41. Jang, J.-H.; Yan, W.-M.; Liu, H.-C. Natural convection heat and mass transfer along a vertical wavy surface. Int. J. Heat Mass Transf. 2003, 46, 1075-1083. [CrossRef]

42. Serrano-Arellano, J.; Xamán, J.; Álvarez, G.; Gijón-Rivera, M. Heat and mass transfer by natural convection in a square cavity filled with a mixture of Air-CO2. Int. J. Heat Mass Transf. 2013, 64, 725-734. [CrossRef]

43. Murthy, P.V.S.N.; Singh, P. Heat and mass transfer by natural convection in a non-Darcy porous medium. Acta Mech. 1999, 138, 243-254. [CrossRef]

44. Ahmadi, S.F.; Spohn, C.A.; Nath, S.; Boreyko, J.B. Suppressing Condensation Frosting Using an Out-of-Plane Dry Zone. Langmuir 2020, 36, 15603-15609. [CrossRef] [PubMed]

45. Sharma, C.S.; Stamatopoulos, C.; Suter, R.; von Rohr, P.R.; Poulikakos, D. Rationally 3D-Textured Copper Surfaces for Laplace Pressure Imbalance-Induced Enhancement in Dropwise Condensation. ACS Appl. Mater. Interfaces 2018, 10, 29127-29135. [CrossRef] [PubMed]

46. Castillo, J.E.; Huang, Y.; Pan, Z.; Weibel, J.A. Asymmetric solidification during droplet freezing in the presence of a neighboring droplet. Int. J. Heat Mass Transf. 2021, 171, 121134. [CrossRef]

47. Lo, C.-W.; Chu, Y.-C.; Yen, M.-H.; Lu, M.-C. Enhancing Condensation Heat Transfer on Three-Dimensional Hybrid Surfaces. Joule 2019, 3, 2806-2823. [CrossRef] 